\title{
Human Values and Retirement Experiences: a Longitudinal Analysis of Norwegian Data
}

\author{
Morten Blekesaune ${ }^{1}$ (D) Thomas Hansen $^{2}$
}

Accepted: 15 April 2021 / Published online: 22 April 2021

(c) The Author(s) 2021

\begin{abstract}
Motivational factors, such as one's value system, may affect how people cope with the opportunities and challenges of retirement. This article explores the moderating roles of Schwartz's four basic values (self-enhancement, self-transcendence, openness to change, and conservation) on the magnitude and duration of retirement effects on life satisfaction between two waves (2007 and 2017) of the Norwegian Life course, Ageing and Generation (NorLAG) study. Fixed-effect regression analyses are run separately for men and women to account for gender differences in the attachments and identities tied to work and nonwork domains. Retirement is not a uniform experience, and findings show that retirement experiences are structured by gender and personal values. Holding values with a personal focus (self-enhancement and openness to change) is associated with less beneficial effects of retirement among men but not among women. Men holding these values may struggle to find new and stimulating avenues for experiencing personal success and variety after retirement. Holding values with a social focus (self-transcendence and conservation) is unrelated to retirement effects.
\end{abstract}

Keywords Retirement · Human values · Life satisfaction · Gender · Longitudinal

\section{Introduction}

Retirement is a major life transition with potentially broad and substantial effects on quality of life. It entails radical changes in social roles, lifestyles, and daily activities, and confronts individuals with new expectations, challenges, and opportunities, all of which can influence well-being (Wang \& Shi, 2014). Many changes are likely to confer substantial benefits, such as more freedom and time to pursue meaningful and satisfying activities and social relationships (Reitzes \& Mutran, 2004; Szinovacz \& Davey, 2006; Wanka, 2020). At the same time, other aspects, such as disengagement from work-related networks, inactivity, boredom, and loss of status and identity, can compromise well-being.

Morten Blekesaune

morten.blekesaune@uia.no

1 University of Agder, Kristiansand, Norway

2 Norwegian Social Research (NOVA), Oslo Metropolitan University, Oslo, Norway 
Several studies have investigated changes in well-being associated with the transition to retirement. A recent review concluded that although retirement has little impact on the well-being of the average worker, this pattern masks considerable diversity (Henning et al., 2016). Typically, studies show that the majority of retirees maintain stable levels of life satisfaction; a smaller group experience an increase, while a third group experience a decline in life satisfaction after retirement (Heybroek et al., 2015; Pinquart \& Schindler, 2007; Wang, 2007).

The adjustment to retirement varies by access to social and economic resources that shape the conditions of retirement (Hansson et al., 2018; Muratore et al., 2014; Pinquart \& Schindler, 2007; Wang, 2007; Wang et al., 2011). For example, better health, access to social support, and higher education and income have been related to more positive changes in life satisfaction associated with the transition (for reviews, see Heybroek et al., 2015; Barbosa et al., 2016). Few studies have investigated retirement adjustments in relation to motivational factors. Motivational factors, such as one's value system, may help us understand how older workers relate and respond to the opportunities and challenges of retirement (van Solinge, 2013).

This article contributes to the literature on retirement adjustments by investigating the moderating roles of motivational factors measured by basic human values (Schwartz, 2012). Using panel data over 10 years, we explore how human values shape well-being trajectories following retirement. Because embedding the retirement transition within human values is a new development, we also examine whether the effects of human values are independent or overlap with the effects of well-known determinants of retirement adjustment, such as health and socio-economic status. All models are estimated separately for men and women, to account for the differences in work histories, social integration, and social roles and expectations between men and women,

We study adjustment and well-being in terms of life satisfaction, that is, the cognitive component of subjective well-being (Diener et al., 1999). Life satisfaction is typically conceptualized as an overall assessment of one's quality of life, and can be understood as an assessment based upon comparisons of actual achievements with conditions one aspires to (Andrews \& Withey, 1976; Diener et al., 1999). Life satisfaction as a proxy for overall well-being is particularly suited to gauging the success of adjustment to life events such as retirement (van Solinge, 2013; Wetzel et al., 2016). Although adaptation effects are evident across all dimensions of well-being, research has indicated that life events have a stronger effect on cognitive than affective facets of well-being (Luhmann et al., 2012; see Hansen, 2010 for a review).

\section{Human Values and Retirement}

Human values indicate what people believe is important in their lives (Inglehart, 1997; Schwartz, 2012). As such, values are motivational constructs that guide people in how they evaluate or relate to certain activities and life domains (e.g. work, family, and leisure). Basic human values are trans-situational goals that serve as criteria for making judgements about these activities or life domains rather than presenting such judgements directly (Rokeach, 1973; Schwartz, 1992). Because they are trans-situational, human values are more independent variables than the evaluations of various life domains that likely reflect plans and decisions towards retirement. 


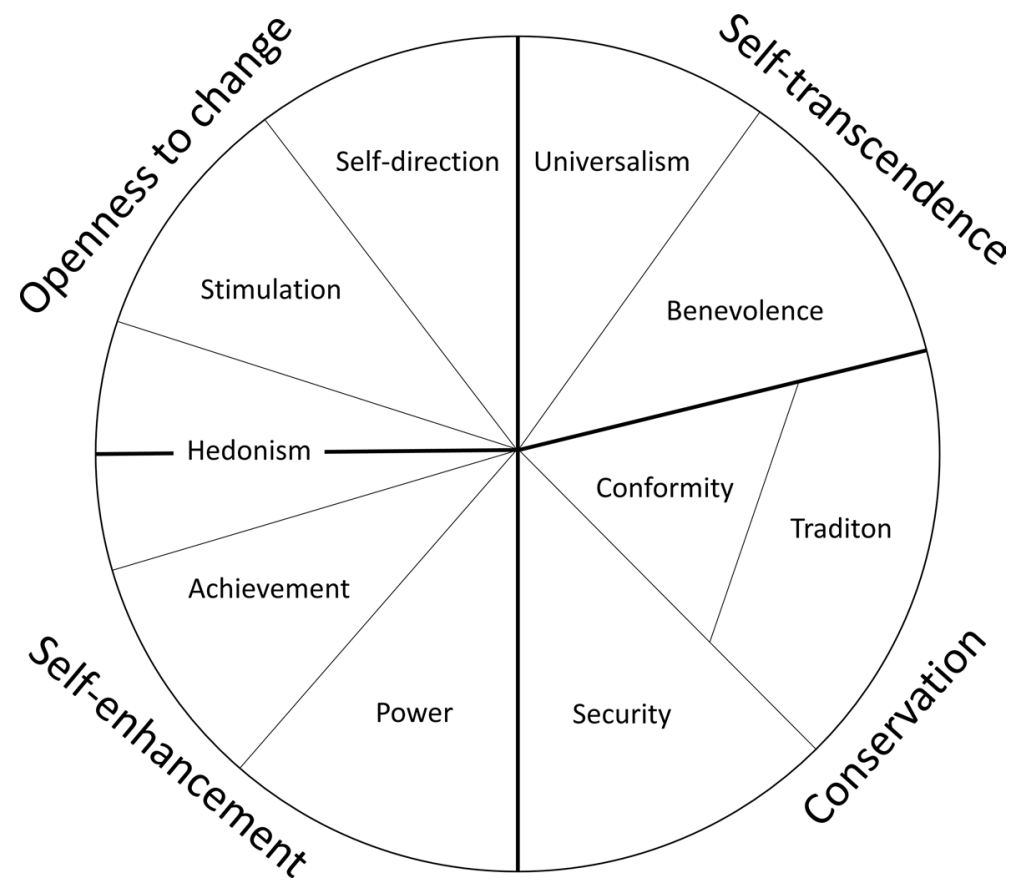

Fig. 1 The basic human values in the Schwartz taxonomy

Motivational factors, such as one's value system, may affect how people cope with retirement. For example, retirement represents a shift from structured to unstructured time (Burr et al., 2011), and motivational factors can influence how people cope with or take advantage of the new freedom and reduced social control and structure in life. According to the value congruity perspective (Sagiv \& Schwartz, 2000; Sagiv et al., 2004), people are likely to experience well-being when they can express and fulfil whatever needs are important to them. Hence, values may act as moderators in the link between activities and life satisfaction. Activities are satisfying to the extent they are consistent with important values (Burr et al., 2011; Oishi et al., 1999). Similarly, retirement can be a hallmark of the transition to 'old age' and an introduction to the realities of aging (Burr et al., 2011). In this context, core values may play a critical role in how people deal with the loss of the worker role and associated social ties and also the need to establish a new and satisfying lifestyle.

Schwartz identified 10 basic human values, which reflect a set of four higher-order values: self-enhancement (the pursuit of status, success, and dominance over others), openness to change (the search for stimulation, and autonomous behavior), self-transcendence (concern for the welfare of others, for the community, and for the natural world), and conservation values (security, tradition, and conformity, including religious and family values) (Fig. 1). The dimensions of this value taxonomy have been validated in more than 80 cultural groups, using diverse samples and measures (Schwartz, 2012). Longitudinal data indicate that an increase in the importance of one value is typically accompanied by an increase in the importance of compatible values and a decrease in the importance of conflicting values (Bardi et al., 2009).

The four higher-order values can be conceptualized to form two bipolar dimensions (Schwartz, 1992, 2012). One contrasts self-enhancement with self-transcendence values 
(Fig. 1). It concerns the conflict between personal interest and collective welfare. The other contrasts openness to change with conservation values. It concerns the conflict between independence and obedience. Schwartz et al. (2012) have also introduced a contrast between values with a personal focus (openness to change and self-enhancement) and those with a social focus (conservation and self-transcendence). In other value paradigms, self-enhancement values are consistent with materialistic values, and openness-to-change values are consistent with variety-seeking (Burroughs \& Rindfleisch, 2002). Similarly, self-transcendence values are consistent with community values, and conservation values are consistent with religious and family values (ibid.).

\subsection{Self-Enhancement}

Self-enhancement values refer to the pursuit of success, power, admiration, and pleasure or sensual gratification. Self-enhancement is typically viewed as a type of motivation that enables people to feel good about themselves and to maintain self-esteem (Sedikides \& Strube, 1995). In the context of the transition to retirement, holding self-enhancement values may induce difficultly in coping with the loss of a work role that has been important for identity and for experiencing meaning and growth. Hence, in the post-retirement years, self-enhancement values may create goal frustration and negative emotions because valued goals, such as economic success, recognition for accomplishments, and control over others, may become difficult to attain (Burr et al., 2011).

\subsection{Self-Transcendence}

Self-transcendence values emphasize the preservation and enhancement of other people and of nature. Being concerned about the welfare of others and the natural world, while unrelated to well-being among younger and working adults (Sagiv \& Schwartz, 2000), may be beneficial for older and retired adults because these values are consistent with presentoriented, emotionally meaningful, and affiliative goals (Carstensen et al., 1999). Workers holding self-transcendence values may find it easy to cope with retirement because they see their family, friends, or voluntary work as arenas where they can transcend selfish concerns and promote the welfare of others (Schwartz, 1992).

\subsection{Openness to Change}

Openness-to-change values refer to the pursuit of independence, creativity, and intellectual and emotional stimulation and directions, including those with unpredictable outcomes (Schwartz, 2020). Individuals holding openness-to-change values may find it difficult to cope with the loss of a job, insofar as their work offers stimulating directions, or if they find it difficult to replace job-related directions after retirement. Openness-to-change values may, however, create opportunities to engage in new satisfying activities and interactions, which, in turn, may promote well-being after retirement.

\subsection{Conservation}

Conservation values refer to subordination to socially imposed expectations, the pursuit of security and stability, and upholding tradition and customs (Schwartz, 1992, 2012). 
Conservation values may become increasingly important over the lifespan, as indicated by their greater emphasis among older adults (Caprara et al., 2003). People holding conservation values may cope well with retirement because it promotes opportunities to cultivate stable and lasting relationships. Conservation values may also be linked to enhanced wellbeing among older people through their emphasis on tradition or religion, which may provide social connectedness, purpose, and meaning.

\section{Gendered Social Roles}

Retirement may affect men and women differently. Several notions predict that women will cope better with retirement than men. First, women's greater life-course involvement with children and family relationships can provide them with a relative advantage. This involvement suggests that women are more prepared for retirement because of previous experiences with role transitions and interrupted careers (Aisenbrey et al., 2009; Lundberg \& Rose, 2000), the saliency of family roles for identity and self-esteem (Chan \& Elder, 2000; Luo et al., 2014), and access to alternative social roles (Barnes \& Perry, 2004). Moreover, as employed women tend to experience greater role strain and work-family conflict than employed men (Hansen et al., 2013; Kim \& Moen, 2002), they may benefit more from exiting the working role. At the same time, men's lower number of role involvements suggests greater negative impacts of retirement, as per the notions of role enhancement theory (Kim \& Moen, 2002).

These effects may vary with human values. Retirement can be predicted to be difficult for individuals who hold values with a personal focus (self-enhancement and openness to change) and at the same time have few alternative sources of identity and meaning beyond their working role. One may thus assume, given men's generally greater priority and emphasis on paid work, that holding these values can lead to harmful retirement effects for men in particular. Furthermore, holding values with a social focus (self-transcendence and conservation) may promote well-being after retirement, especially for those susceptible to role overload and role conflict before retirement. As employed women report more work-family conflict than their male counterparts, women with social values may especially benefit from retirement as it provides more freedom to experience and enjoy a stable lifestyle and to pursue opportunities to promote the welfare of others (e.g. grandparenting or volunteer work).

\section{Lifespan Theories on Motivation}

Lifespan development theories propose that priorities and goals change in later life. Socioemotional selectivity theory (Carstensen et al., 1999) argues that motivations are related to perceptions of future time. Because greater age means that future time is perceived as limited, older people shift their priorities from future-oriented to present-oriented goals, aimed at regulating emotions and maximizing meaningful and rewarding activities and social interaction. For example, research has shown that older adults tend to drop or distance themselves from less intimate relationships and increase their emotional investments in relationships with significant others (ibid.).

Furthermore, adult development theory argues that supporting and guiding the next generation, labelled 'generativity', is associated with better psychosocial development and 
mental health (Erikson, 1963). The opposing tendency is obsessive self-indulgence, which is thought to be damaging for healthy development in later life. Research shows that generativity is conducive to later-life well-being (Azarow, 2003). Generativity is consistent with self-transcendence and conservation values in the Schwartz taxonomy, while self-indulgence is consistent with self-enhancement and openness-to-change values. Hence, aging processes generally, and retirement more specifically, could be more beneficial to later-life developments among individuals holding self-transcendence and conservation values than to those holding self-enhancement and openness-to-change values.

The benefits of generativity (and values with a social focus) may be especially evident for women, given their traditionally greater involvement in family roles, including grandparenting (Chan \& Elder, 2000; Luo et al., 2014). There is also the possibility that the detrimental effect of obsessive self-indulgence could be more relevant to male workers because they tend to have spent more time in paid work and less time on family relationships compared with their female counterparts. Taken together, lifespan theories of motivation and gender role theory suggest that retirement may be especially beneficial to women holding self-transcendence and conservation values and to men with a low emphasis on self-enhancement and openness-to-change values.

\section{Previous Research}

Retirement is a crucial transition in later life and much theoretical and empirical attention has been paid to its effect on health and well-being. Various theories provide very different implications. For example, a role theory perspective would argue that retirement, due to the loss of an important role and other resources, is a 'crisis' with detrimental effects on self-worth and well-being (George \& Maddox, 1977). Continuity theory (Atchley, 1999), by contrast, argues that retirement will have little effect on well-being because people are highly motivated to replace lost roles in order to maintain stability in their lifestyles, engagements, and ultimately well-being in later life.

Empirical research has shown that retirement has little effect on the well-being of the average worker (see Henning et al., 2016 for a review). This finding suggests that retirement has costs and benefits that tend to cancel each other out at the individual or group level (Luhmann et al., 2012). However, much of this research has limitations, such as reliance on cross-sectional data and inattention to heterogeneity (e.g. in gender roles and human motivation). Still, some studies have investigated the impact of retirement longitudinally, and others have investigated different social groups. For example, Jæger and Holm (2004 found that retirement may affect men negatively $(p=0.06)$ but seemingly not women.

Some studies on retirement adjustments have also distinguished between short- and longer-term effects and to what extent people adapt and return to their 'baseline' (preretirement) level of well-being, as argued by proponents of hedonic adaptation theory (Brickman \& Campbell, 1971) and set point theory (Diener et al., 2006). Findings indicate that the trajectories of well-being following retirement vary and that there are temporal aspects in how seniors cope with retirement (e.g. Muratore et al., 2014; Pinquart \& Schindler, 2007). One review study found no clear difference between short- and long-term effects (Henning et al., 2016). Individual studies, however, have suggested that the effects of retirement on well-being are predominantly short-term (Wetzel et al., 2016). A metaanalysis of 13 studies found a small decrease at retirement followed by an adjustment to 
the baseline level (Luhmann et al., 2012). Still, it is not clear if these findings hold for all groups of retirees (e.g. men and women).

There is seemingly little previous research on the role of human values in the adjustment to retirement or on the well-being of retirees more generally. In a study of 373 recent Canadian retirees, Burr and colleagues (2011) found more positive affect among retirees who were high in self-transcendence, openness-to-change, and conservation values, and more negative affect in retirees who were high in self-enhancement and low in opennessto-change values.

\section{Institutional Arrangements}

Norway is an interesting case for investigating the relationship between motivation and retirement adjustments because its pensions system is relatively simple (compared with those of many other countries), with the bulk of pension entitlements being either universal or negotiated at the country level across occupations and industries. Nearly all individuals should be allowed to work till they were 70 years during the study period, and to take an old-age pension at 67 years. About $80 \%$ of employees had early retirement plans that allowed them to retire from 62 years, typically with a lower pension than if retiring later, and everyone could apply for a disability pension at any age below 67 if health problems prevented them from working. Replacement rates would typically vary from 55 to 66 percent depending on occupational pensions.

The Norwegian pension system has always offered some prospects of combining work with the receipt of a pension. These prospects improved somewhat during the study period with the gradual introduction of a new pension system. One consequence is that the receipt of a pension is no longer a valid indicator of retirement behavior because the 'pensioner' can be in full employment.

\section{Hypotheses}

From the theory and research presented above, we hypothesize that retirement adjustments, investigated as changes in life satisfaction, will be predicted by:

(1) Self-enhancement and openness-to-change values (negative effects)

(2) Self-transcendence and conservation values (positive effects).

We also hypothesize that:

(3) Effect (1) will be stronger in men than in women

(4) Effect (2) will be stronger in women than in men

(5) Effects (1) to (4) will tend to diminish with time after retirement.

\section{Method}

\subsection{Data}

Data come from the Norwegian Life course, Ageing and Generation (NorLAG) study (Slagsvold et al., 2012). NorLAG is a population-based sample drawn from the 
Table 1 Descriptive statistics of observations (in both 2007 and 2017) for all 5207 participants (upper part) and for the 862 participants who retired between 2007 and 2017 (lower part of the table)

\begin{tabular}{lccrrll}
\hline & \#obs & \#ind & Mean & S.D & Low & High \\
\hline Life satisfaction & 10,414 & 5207 & 8.4 & 1.5 & 0 & 10 \\
Age (years) & 10,414 & 5207 & 59.4 & 10.4 & 40 & 85 \\
Physical health & 10,414 & 5207 & 4.9 & 1.0 & 1.1 & 6.7 \\
Self-enhancement & 1726 & 863 & 3.3 & 0.7 & 1.5 & 5.8 \\
Openness to change & 1726 & 863 & 3.7 & 0.7 & 1.8 & 6.0 \\
Self-transcendence & 1726 & 863 & 4.6 & 0.6 & 1.6 & 6.0 \\
Conservation & 1726 & 863 & 4.3 & 0.7 & 1.3 & 6.0 \\
Retirement age & 1726 & 863 & 66.2 & 3.4 & 50 & 75 \\
Partnered & 1726 & 863 & 0.8 & 0.4 & 0 & 1 \\
Education (years) & 1726 & 863 & 3.9 & 2.4 & 0 & 8 \\
Income change & 1726 & 863 & 6.9 & 1.7 & 4 & 10 \\
Physical health & 1726 & 863 & 5.0 & 0.7 & 1.1 & 5.9 \\
\hline
\end{tabular}

non-institutionalized population. The data were collected by Statistics Norway via telephone interviews, postal questionnaires (web-based in NorLAG-3), and register information (e.g. education, marital status, and income from sources such as work, benefits, and pensions). The response rate of the first round of NorLAG (in 2002) was $67 \%(n=5,559)$.

We use data from round 2 (in 2007) and round 3 (in 2017) of the NorLAG panel study. Age varied from 40 to 85, with a mean of 59 years (Table 1). We analyse 10,414 observations for 5,207 individuals who participated in both rounds and provided complete information on life satisfaction and physical health, as collected in telephone interviews in both years.

\subsection{Variables}

The dependent variable, life satisfaction, was investigated with a single item: 'On a scale of 0 to 10 , where 0 means "not satisfied at all" and 10 means "very satisfied", how satisfied are you with everything in your life right now?' The responses had a mean value of 8.4, and more than $90 \%$ responded with a value of 7 or higher and less than $1 \%$ with 3 or lower.

Life satisfaction increases sharply between the ages of 50 and 70 (Fig. 2). Longitudinal aging effects show an S-shaped pattern that looks quite similar for men and women, with one crucial difference. The aging effect tilts in an even more favorable direction with increasing age for men than for women. The difference is statistically significant at the $1 \%$ level if using an interaction term between gender and linear age.

Data on physical health were collected from the Short Form 12-scale (Ware et al., 1996) in telephone interviews and divided by 10 to make regression coefficients more visible (by skipping one decimal place).

The principal explanatory variables were the four higher-level human values in the Schwartz taxonomy: self-enhancement, openness-to-change, self-transcendence, and conservation values. A postal and self-administrated questionnaire that included 21 'portraits' (personas) was sent to all respondents who participated in the telephone interview in 2007. The first (of 21) portraits was: 'It is important to this person to ... think up new ideas and to do things in one's own way'. The six possible responses varied from 'Very much like me' to 'Not like me at all'. The items were similar to those used in the European Social 


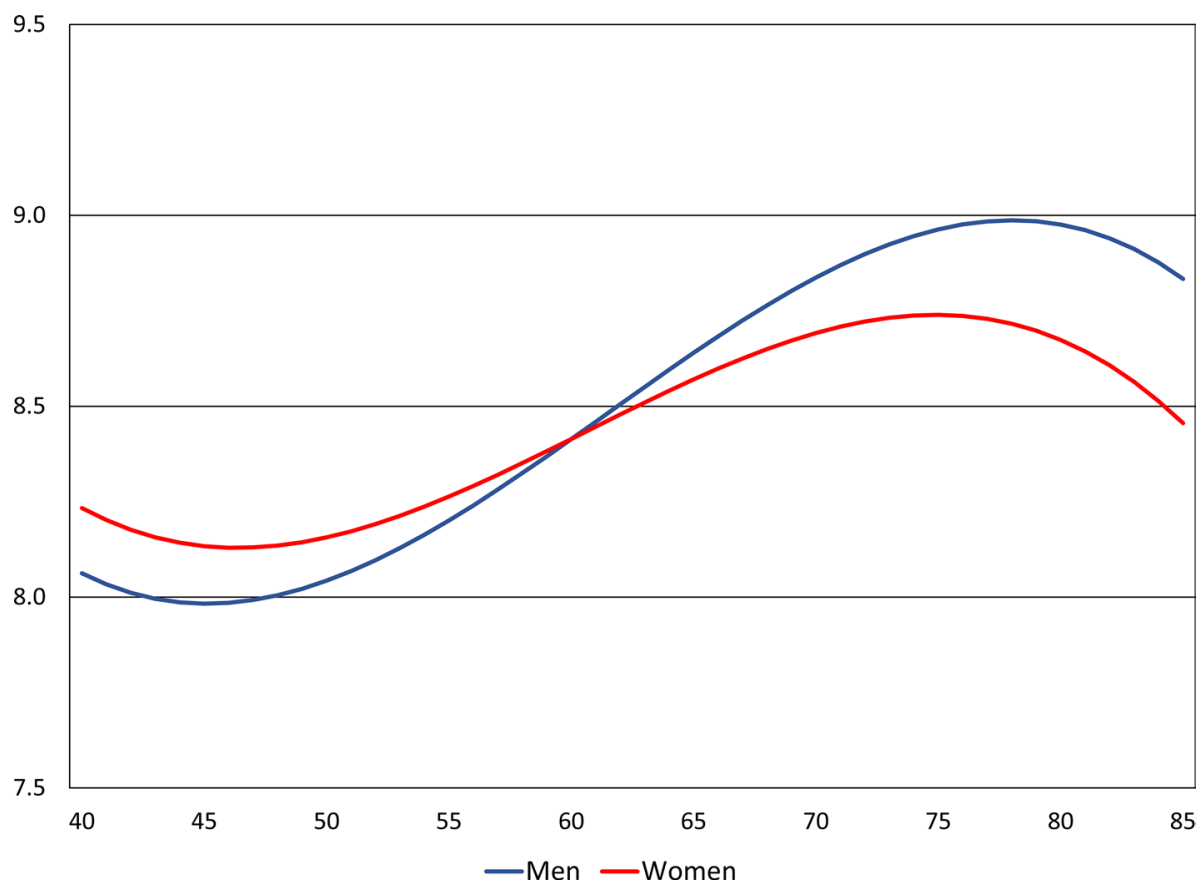

Fig. 2 Changes in life satisfaction by age, longitudinal estimates, men and women in Norway (no statistical controls)

Survey, but sometimes made shorter and gender-neutral. Each of the four value scales was investigated as the mean values of their typically five (4-6) balanced items.

\subsection{Analytical Strategy}

We identified retirement as a transition between two main sources of income, from work income to pension income. Pensions could be for old age, early retirement, or disability. Incomes from three sources were calculated as moving averages for two calendar years each: work, benefits (typically for sickness and unemployment, excluding disability pension), and pensions (including disability pension), with a minimum of approximately 10,000 euros for each source of income (adjusted for year-by-year changes in prices and wages over the study period). Income was below the threshold for only 195 observations, and only transitions from work to pension income were investigated in the statistical models. For those with multiple income sources (e.g. work and pension), the highest source of income was used. Some temporary benefits for sickness and unemployment were classified as income from work and not as benefits.

The data were investigated using panel regression models with fixed effects for individuals (within people's lives; Allison, 2009). The statistical models controlled for age (linear, squared, and cubic terms), physical health, and transitions from work to retirement, using a dummy variable.

The panel regression models investigated how far human values affect the associations between retirement and life satisfaction. These issues were investigated among those 
moving from work to retirement between 2007 and 2017 at ages between 50 and 75 and who also completed at least one of the four human value scales in 2007 (i.e. before retiring). Fixed-effects regression models cannot estimate the effects of variables that do not change between the two rounds of data. Still, they can estimate interaction terms between a non-changing variable (i.e. human values collected in 2007) and the transition from work to retirement. Altogether, 863 workers retired from work to drawing a pension(s) as their main source of income in the 10-year period and also completed the responses required for calculating the four human value scales. The statistical models were controlled for general changes in life satisfaction and physical health among all people aged 40 to 85 years. ${ }^{1}$

Further analyses concentrated on human values that showed statistically significant interactions with retirement on life satisfaction. Here, we also investigated the duration (in years) of retirement effects and whether an effect on life satisfaction was offset by a tendency to return to previous levels of satisfaction over the five years after retirement.

Follow-up analysis also investigated how far further individual characteristics among these 863 workers could help explain how they managed to adjust to retirement, measured as a change in life satisfaction. These further individual characteristics were retirement age; education level, measured as years beyond the compulsory education customarily required to take the highest level achieved; post-retirement income (typically a pension) in relation to pre-retirement income (using $40 \%$ and $100 \%$ thresholds, with values from 4 to 10 in the data); and physical health (12-scale Short Form) using the mean values from 2007 and 2017. This analysis also investigates how far motivational factors overlap with other factors in explaining how older workers adapt to retirement, or if these are independent factors. Finally, we explored the effects of the sub-dimensions of human values that showed statistically significant interactions with retirement on life satisfaction.

\section{Results}

\subsection{General Tendencies}

We present panel regression results indicating how a change in an explanatory variable (e.g. age or health) is associated with a change in life satisfaction within people's lives. Changes in the life satisfaction of older workers are correlated with changes in physical health and with ageng. Life satisfaction increases between the ages of 50 and 70 (see Fig. 2). For both sexes combined, a unit (one standard deviation) decrease in physical health is associated with an approximately 0.26 reduction in life satisfaction along its $0-10$ scale. When controlling for aging effects, female workers report a 0.18 reduction in life satisfaction after retirement compared with before, while male workers report a non-significant reduction in life satisfaction (Table 2). There are no tendencies in the data of a return

\footnotetext{
1 The dependent variable, life satisfaction, is not symmetrical. The fixed-effects model investigated how life satisfaction changed between the two rounds of the NorLAG panel study, and this change is symmetrical and close to normal. It has nearly twice the number of values compared to the original 11-point scale. Test statistics were robust for heterogeneity, and they corrected for the non-independence of the two observations for each respondent using the cluster option in Stata. Main findings regarding interaction terms between retirement and human values were also investigated using ordinal logit fixed-effects models (using the Stata macro feologit) with results consistent with those presented in the results section.
} 
Table 2 Changes in life satisfaction associated with transitions into retirement

\begin{tabular}{lll}
\hline & Men & Women \\
\hline Age (years/10) & $4.88^{* *}(1.4)$ & $5.62^{* *}(1.5)$ \\
Age squared & $-0.85^{* *}(.24)$ & $-0.98^{* *}(.25)$ \\
Age cubic & $-0.04^{* *}(.01)$ & $-0.05^{* *}(.01)$ \\
Work $\rightarrow$ retirement $^{\mathrm{a}}$ & $-0.05(.08)$ & $-0.18^{*}(.09)$ \\
Years after retirement $^{\mathrm{b}}$ & $-0.02(.02)$ & $0.01(.02)$ \\
Physical health & $0.29^{* *}(.04)$ & $0.23^{* *}(.04)$ \\
\hline
\end{tabular}

${ }^{\mathrm{a}}$ Coded $1 \& 0 ;{ }^{\mathrm{b}} 0-5$ range; $* p<0.05, * * p<0.01$ (in two-sided tests)

towards pre-retirement levels of life satisfaction during the first five years after retirement when also controlling for general aging effects.

\subsection{Motivational Factors}

Table 3 shows how the retirement effects on life satisfaction interact with the four basic human values. These interaction effects are estimated in separate statistical models for each human values scale; models are otherwise similar to those used in Table 2 except that the slope (years after retirement) variable is excluded. Among men, retirement has more negative effects for individuals who rate highly in self-enhancement and openness-to-change values. There are no similar findings among female workers, where the tendencies are in opposite directions, at least for openness-to-change values. There is collinearity between the self-enhancement and openness-to-change values among male workers in this analysis. Because they are estimated in separate models, they should be interpreted jointly and not additively.

Table 4 investigates whether male workers holding self-enhancement and openness-tochange values tend to return to previous levels of life satisfaction over the years after retirement. There are no such tendencies in the data.

Next, we investigate how far retirement experiences are also associated with other individual characteristics (additional to self-enhancement and openness-to-change values) among male workers. Retirement is more beneficial for individuals with a higher educational level (Table 5). The interaction term with physical health is marginally non-significant, even when removing the (significant) current health effect in these models. None of these additional interaction effects can help explain why male workers holding selfenhancement and openness-to-change values are less satisfied as retirees. They appear to have independent effects.

\subsection{Subscales}

A final analysis investigates the effect of the five human values that are part of the two higher-level human values investigated above (see Fig. 1): power, achievement, hedonism, stimulation, and self-direction. The results (Table 6) indicate that four of these five values are associated with less successful adjustments to the retirement of male workers. The sole exception is for power: having expensive things and being able to control others. Another 
finding is that effect sizes appear to be larger for the more general values-self-enhancement and openness to change- than for the more specific values, given that they are measured along the same six-point scale and the fact that the test statistics are slightly stronger for the higher-level scales. Again, because of collinearity between them, they should be interpreted jointly. The results indicate that the values on the left-hand side of the Schwartz value taxonomy in Fig. 1 make a difference to how male workers adapt to retirement.

\subsection{Partial Retirement}

We have identified retirement as a transition in the main source of income from work to a pension. A considerable number of older workers and recent pensioners combine work and pension: $12 \%$ of the older workers retiring in our study (106 of the 863) were gradually retired before retirement in 2007 because they also received a pension above 10.000 euro; $17 \%$ of the retirees were gradually retired after our retirement indicator in 2017 because they also received some work-related income above 10.000 euro. Only $1.6 \%$ of the retirees (14 of 863) were gradually retired both in 2007 and 2017. The interaction terms with selfenhancement values and openness-to-change values from Table 3 do not change if leaving out those being gradually retired before retirement (in 2007) from the empirical analysis (Table 7). However, both interaction terms become weaker when leaving out those who were gradually retired after retirement (in 2017).

\section{Discussion}

Retirement is not a uniform transition, and much theoretical and empirical work has been devoted to understanding the different risks and experiences associated with retirement. Research has shown that some variation can be accounted for by access to economic and social resources. Building on prior theoretical work (van Solinge, 2013; Wang, 2007), we suggested that motivational factors could also play a role in people's adjustments to retirement. However, few studies have investigated this issue systematically, and we identified only one previous study that investigated this issue using basic human values (Burr et al., 2011).

The current study shows that retirement is associated with a small decrease in life satisfaction, after accounting for the larger positive effects of aging. The negative effect of retirement is somewhat larger, albeit not statistically significantly so, for women than for men. The positive effect of aging is larger in men than in women. The net effects of both aging and retirement appear to balance each other out for a majority of women, while producing a net positive effect in a majority of men.

There is a possibility that the positive aging effect surrounding the years when most people retire is related to retirement. Many people look forward to their retirement, and they might enjoy the opportunities for some changes in daily activities associated with retirement even if the event of retirement is associated with a slight decrease in life satisfaction. From this perspective, it is interesting that the moderating effects of motivational factors on retirement adaptations are not temporary but seemingly lasting.

We find that the changes in life satisfaction associated with retirement depend on human value orientations, but only among men. The findings suggest that male workers holding openness-to-change and self-enhancement values have more adjustment problems as retirees than other men. It supports our first hypothesis, but only for men, and thus also 


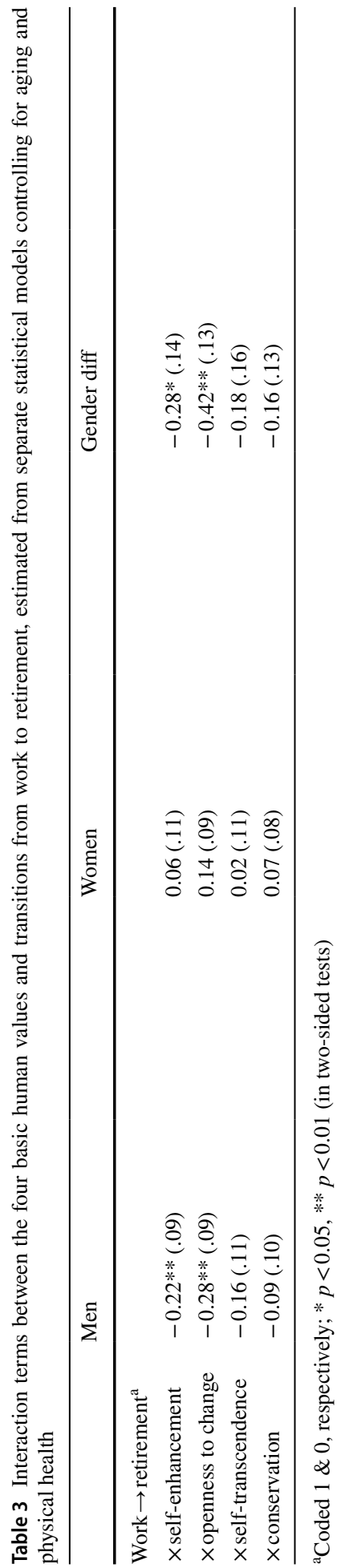


Table 4 Changes in life satisfaction associated with transitions into retirement among male workers, adding slope (years after retirement)
Table 5 Changes in life satisfaction associated with transitions into retirement among male workers, adding further characteristics that also interact with retirement transition

\begin{tabular}{lllll}
\hline & Model 1 & \multicolumn{3}{c}{ Model 2 } \\
\hline Age (years/10) & $-5.95^{* *}$ & $(1.6)$ & $-6.10^{* *}$ & $(1.6)$ \\
Age squared & $1.04^{* *}$ & $(.27)$ & $1.07^{* *}$ & $(.26)$ \\
Age cubic & $-0.06^{* *}$ & $(.01)$ & $-0.06^{* *}$ & $(.01)$ \\
Work $\rightarrow$ retirement $^{\mathrm{a}}$ & $0.64^{*}$ & $(.30)$ & $0.95^{* *}$ & $(.34)$ \\
Physical health & $0.31^{* *}$ & $(.04)$ & $0.31^{* *}$ & $(.04)$ \\
Work $\rightarrow$ retir. $\times$ self-enhancement & $-0.22^{*}$ & $(.09)$ & - & - \\
Years after $\times$ self-enhancement & -0.00 & $(.01)$ & - & - \\
Work $\rightarrow$ retir. $\times$ openness to ch & - & - & $-0.28^{* *}$ & $(.09)$ \\
Years after $\times$ openness to change & - & - & -0.00 & $(.01)$ \\
\hline
\end{tabular}

${ }^{\mathrm{a} C o d e d} 1 \& 0$, respectively; $* p<0.05 \& * * p<0.01$ (in two-sided tests)

\begin{tabular}{lllll}
\hline & Model 1 & \multicolumn{3}{l}{ Model 2 } \\
\hline Age (years/10) & $-5.93^{* *}$ & $(1.6)$ & $-6.00^{* *}$ & $(1.5)$ \\
Age squared & $1.04^{* *}$ & $(.26)$ & $1.05^{* *}$ & $(.26)$ \\
Age cubic & $-0.06^{* *}$ & $(.01)$ & $-0.06^{* *}$ & $(.01)$ \\
Work $\rightarrow$ retirement $^{\mathrm{a}}$ & 0.50 & $(.73)$ & 1.00 & $(.76)$ \\
Physical health & $0.31^{* *}$ & $(.04)$ & $0.31^{* *}$ & $(.04)$ \\
Work $\rightarrow$ retirement & & & & \\
$\times$ self-enhancement & $-0.26^{* *}$ & $(.09)$ & - & - \\
$\times$ openness to change & - & - & $0.34^{* *}$ & $(.08)$ \\
$\times$ retirement age & -0.03 & $(.02)$ & -0.03 & $(.02)$ \\
$\times$ partnered & -0.21 & $(.18)$ & -0.28 & $(.18)$ \\
$\times$ education level (years) & 0.04 & $(.03)$ & $0.05 \dagger$ & $(.03)$ \\
$\times$ income change & -0.06 & $(.04)$ & -0.06 & $(.04)$ \\
$\times$ physical health & 0.14 & $(.10)$ & 0.13 & $(.10)$ \\
\hline
\end{tabular}

${ }^{\mathrm{a} C o d e d} 1 \& 0 ; \dagger \mathrm{p}<0.1, * p<0.05 \& * * p<0.01$ (in two-sided tests)

\begin{tabular}{lll}
\hline Work $\rightarrow$ retirement & & \\
\hline$\times$ power & -0.08 & $(.08)$ \\
$\times$ achievement & $-0.15^{*}$ & $(.07)$ \\
$\times$ hedonism & $-0.16^{* *}$ & $(.06)$ \\
$\times$ stimulation & $-0.14^{*}$ & $(.07)$ \\
$\times$ self-direction & $-0.15^{*}$ & $(.07)$ \\
\hline
\end{tabular}

${ }^{\mathrm{a}}$ Coded $1 \& 0$, respectively; $* p<0.05 \& * * p<0.01$ (in two-sided tests); estimated from separate statistical models that also control for aging and physical health
Table 6 Interaction terms between five specific human values (part of self-enhancement and openness-to-change values) and transitions from work to retirement among male workers

the third hypothesis. The comparison with women is complicated because women have a slightly steeper drop in life satisfaction around retirement and a less beneficial aging effect compared with men. Hence, one may argue that retirement does not affect the life 
Table 7 Interaction terms between human values and transitions from work to retirement in men from models similar to Table 2 when excluding the partially retired

All respondents

Excluding partially retired Excluding parafter tially retired after

Work $\rightarrow$ retirement $^{\mathrm{a}}$

$\times$ self-enhancement

$\times$ openness to change

$-0.22 * *$

(.09)

$-0.23^{*}$

(.09)

$-0.15$

$-0.32 * *$

(.10)

$-0.19 *$

${ }^{\mathrm{a}}$ Coded $1 \& 0$, respectively; ${ }^{*} p<0.05, * * p<0.01$ (in two-sided tests)

satisfaction of men not holding openness-to-change and self-enhancement values, whereas for men holding such values, as well as to women, retirement as such is associated with a drop in life satisfaction.

According to the World Economic Forum (2020), Norway is the country with the second highest gender equality in the world, after Iceland. Many analysts have assumed that as the economic behavior of men and women becomes more similar, male and female motivations should also become similar (Agassi, 1989; Brown, 1970). Following this materialist theory, we would expect motivational factors to make little difference to how men and women adapt to retirement. However, our findings indicate that men and women holding the same openness-to-change and self-enhancement values adapt differently to retirement.

Schwartz (2012) introduced a contrast between values with a personal focus (openness to change and self-enhancement) and those with a social focus (conservation and selftranscendence). This contrast resonates with our findings, as the openness-to-change and self-enhancement values in particular have considerable conceptual and empirical overlap (correlated at $r=0.74$ in the current data). Hence, we must interpret them jointly. These values are unrelated to the situational characteristics in our analysis (i.e. health, retirement age, education, and income levels). Thus, we have good reason to believe that these factors have independent motivational effects, as argued by human value theory (Schwartz, 1992, 2012).

Openness-to-change and self-enhancement values indicate motivations to pursue intellectual and emotional directions to maintain self-esteem and well-being (Schwartz, 2012; Sedikides \& Strube, 1995). Our findings indicate that male workers holding these values may struggle to find new and stimulating avenues for experiencing personal success and variety after retirement. For many men holding openness-to-change and self-enhancement values, the workplace may have represented a vital arena for satisfying needs and fulfilling valued goals related to achieving success and recognition and for seeking varying and stimulating intellectual or emotional pursuits. In contrast, women with similar values may to a larger degree have access to alternative avenues to fulfil these goals-for example, in the domains of family and friends. Hence, men attaching importance and status to work may experience growing feelings of emptiness and dissatisfaction after retirement.

Our findings also indicate that having some income work after retirement could be important to men holding values with a personal focus. However, there is a possibility of reverse causation in such findings: the ability to adapt successfully to retirement might also increase the probability of doing some work after retirement.

Holding values with a social focus (self-transcendence and conservation values) does not seem to be important for how older workers adapt to retirement. Hence, our second hypothesis is not supported by the data, and it makes our fourth hypothesis less elevant. 
Finally, we do not find any tendencies that the effects of human values tend to diminish over time after retirement, meaning that our fifth hypothesis is not supported either.

Previous research has indicated that workers in good health and with higher social and economic resources adapt better to retirement than those with fewer resources (e.g. Wetzel et al., 2016). The current study supports these findings in relation to education and health. The physical health effect is marginally non-significant (when removing current health; ancillary analysis, not shown). However, when also considering previous research (Barbosa et al., 2016; Heybroek et al., 2015), there is every reason to believe that health makes a difference to how older workers adapt to retirement.

Our findings indicate that motivational factors in terms of holding values with a personal focus (openness to change and self-enhancement) are more important for how older men adapt to retirement than their social and economic resources (such as education level and health). The findings also indicate that these are independent effects. In fact, the interaction terms with openness to change and self-enhancement tend to become stronger when controlling for the social and economic resources of older workers.

There is a slight but non-significant tendency in our data that male workers retiring late adapt less successfully to retirement than those retiring earlier (Table 5). This tendency might reflect selection effects: male workers being less likely to adapt successfully to retirement chose to retire later. Still, these results indicate that most older male workers are unlikely to adapt better to retirement if they postpone it. However, this might be different for older workers holding values with a personal focus. Higher-order interaction terms (not shown in tables) indicate that male workers holding self-enhancement values tend to adapt better to retirement when retiring late rather than early. A similar result for male workers holding openness to change values is marginally non-significant. These latter results indicate that male workers holding values with a personal focus tend to adapt better to retirement when retiring late rather than early.

A surprising finding is that declining income following retirement is not associated with how older male workers adapt to retirement. One possible explanation could be that the Norwegian pension system compensates low-income workers better than high-income workers. Low-income male workers are surprisingly well adapted as retirees in Norway when investigating changes in life satisfaction before and after retirement. There is a possibility that these non-findings reflect unobserved characteristics of the jobs held by lowincome male workers-for example, low autonomy and physical job strains.

\subsection{Limitations}

This analysis has only investigated one aspect of subjective quality of life: life satisfaction. Research indicates that the cognitive element of well-being shows more temporal variation than other measures of quality of life, and is often considered the best single indicator of quality of life (Diener et al., 1999; Hansen, 2010). Still, our findings cannot generalize to the dimensions of affective (e.g. happiness, worries) or eudaimonic (e.g. engagement, meaning in life) well-being.

Single-item measures typically show poorer psychometric properties than multi-item scales (e.g. SWLS), and our life-satisfaction item might have some social desirability bias because it was collected in telephone interviews. However, if this or similar types of bias reflect stable characteristics of individuals (e.g. response set), they should also level out in our fixed effects regression models that control for all non-changing characteristics of the 
individuals over the study period. Still, there might even be further non-observed factors that change around the event of retirement which our models do not control for, including those related to the processes leading to retirement. For example, there is the possibility that male workers holding values with a personal focus are more sensitive to the processes leading to retirement than workers with other motivations.

Our findings regarding the role of human values with a personal focus should be the subject of more in-depth analyses that might identify important mechanisms behind these statistical associations. If so, those groups of male workers who currently find it challenging to adapt to retirement could benefit from more awareness and retirement preparations. There is also a need to scrutinize further the well-being dimension, the various processes leading to retirement, why women tend to be less satisfied with their retirement than men, and why the general aging effects appear to be less beneficial to women than to men.

Funding Open access funding provided by University of Agder. This research was supported by the Norwegian Research Council through the research project 'Active ageing-pathways and outcomes' (grant no. 236997).

Open Access This article is licensed under a Creative Commons Attribution 4.0 International License, which permits use, sharing, adaptation, distribution and reproduction in any medium or format, as long as you give appropriate credit to the original author(s) and the source, provide a link to the Creative Commons licence, and indicate if changes were made. The images or other third party material in this article are included in the article's Creative Commons licence, unless indicated otherwise in a credit line to the material. If material is not included in the article's Creative Commons licence and your intended use is not permitted by statutory regulation or exceeds the permitted use, you will need to obtain permission directly from the copyright holder. To view a copy of this licence, visit http://creativecommons.org/licenses/by/4.0/.

\section{References}

Agassi, J. B. (1989). Theories of gender equality: Lessons from the Israeli kibbutz. Gender and Society, $3(2), 160-186$

Aisenbrey, S., Evertsson, M., \& Grunow, S. (2009). Is there a career penalty for mothers' time out? A comparison of Germany, Sweden and the United States. Social Forces, 88(2), 573-605

Allison, P. (2009). Fixed effects regression models. Sage Publications.

Andrews, F. M., \& Withey, S. B. (1976). Social indicators of well-being: Americans' perceptions of quality of life. Plenum Press.

Atchley, R. C. (1999). Continuity and adaptation in aging: creating positive experiences. The Johns Hopkins University Press.

Azarow, J. (2003). Generativity and well-being: An investigation of the Eriksonian hypothesis. Dissertation. Northwestern University.

Barbosa, L. M., Monteiro, B., \& Murta, S. G. (2016). Retirement adjustment predictors: A systematic review. Work, Aging and Retirement, 2(1), 1-19

Bardi, A., Lee, J. A., Hofmann-Towfigh, N., \& Soutar, G. N. (2009). The structure of intraindividual value change. Journal of Personality and Social Psychology, 97(5), 913-929

Barnes, H., \& Perry, J. (2004). Renegotiating identity and relationships: Men and women's adjustments to retirement. Ageing and Society, 24(2), 213-233

Brickman, P., \& Campbell, D. T. (1971). Hedonic relativism and planning the good society. In M. H. Appley (Ed.), Adaptation Level Theory. (pp. 287-302). Academic Press.

Brown, J. K. (1970). A note on the division of labor by sex. American Anthropologist, 72(5), 1073-1078

Burr, A., Santo, J. B., \& Pushkar, D. (2011). Affective well-being in retirement: The influence of values, money, and health across three years. Journal of Happiness Studies, 12(1), 17-40

Burroughs, J. E., \& Rindfleisch, A. (2002). Materialism and well-being: A conflicting values perspective. Journal of Consumer Research, 29(3), 348-370

Caprara, G. V., Caprara, M., \& Steca, P. (2003). Personality's correlates of adult development and aging. European Psychologist, 8(3), 131-147 
Carstensen, L. L., Isaacowitz, D. M., \& Charles, S. T. (1999). Taking time seriously: A theory of socioemotional selectivity. American Psychologist, 54(3), 165-181

Chan, C. G., \& Elder, G. H. (2000). Matrilineal advantage in grandchild-grandparent relations. The Gerontologist, 40(2), 179-190

Diener, E., Suh, E. M., Lucas, R. E., \& Smith, H. L. (1999). Subjective well-being: Three decades of progress. Psychological Bulletin, 125(2), 276-302

Diener, E., Lucas, R. E., \& Scollon, C. N. (2006). Beyond the hedonic treadmill: Revising the adaptation theory of well-being. American Psychologist, 61(4), 305-314

Erikson, E. H. (1963). Childhood and society. Norton.

George, L. K., \& Maddox, G. L. (1977). Subjective adaptation to loss of the work role: A longitudinal study. Journal of Gerontology, 32(4), 456-462

Hansen, T. (2010). Subjective well-being in the second half of life: The influence of family and household resources. Dissertation. University of Oslo, Faculty of Medicine.

Hansen, T., Slagsvold, B., \& Ingebretsen, R. (2013). The strains and gains of caregiving: An examination of the effects of providing personal care to a parent on a range of indicators of psychological well-being. Social Indicators Research, 114(2), 323-343

Hansson, I., Buratti, S., Thorvaldsson, V., Johansson, B., \& Berg, A. I. (2018). Changes in life satisfaction in the retirement transition: Interaction effects of transition type and individual resources. Work, Aging and Retirement, 4(4), 352-366

Henning, G., Lindwall, M., \& Johansson, B. (2016). Continuity in well-being in the transition to retirement. GeroPsych, 29(4), 225-237

Heybroek, L., Haynes, M., \& Baxter, J. (2015). Life satisfaction and retirement in Australia: A longitudinal approach. Work, Aging and Retirement, 1(2), 166-180

Inglehart, R. (1997). Modernization and postmodernization: cultural, economic, and political change in 43 societies. Princeton University Press.

Jæger, M. M., \& Holm, A. (2004). How stressful is retirement? New evidence from a longitudinal, fixedeffects analysis. Center for applied microeconomics.

Kim, J. E., \& Moen, P. (2002). Retirement transitions, gender, and psychological well-being: A lifecourse, ecological model. Journal of Gerontology: Psychological Sciences, 57B(3), 212-222

Luhmann, M., Hofmann, W., Eid, M., \& Lucas, R. E. (2012). Subjective well-being and adaptation to life events: A meta-analysis. Journal of Personality and Social Psychology, 102(3), 592-615

Lundberg, S., \& Rose, E. (2000). Parenthood and the earnings of married men and women. Labour Economics, 7(6), 689-710

Luo, Y., LaPierre, T. A., Hughes, M. E., \& Waite, L. J. (2014). Grandparents providing care to grandchildren: A population-based study of continuity and change. Journal of Family Issues, 33(9), 1143-1167

Muratore, A. M., Earl, J. K., \& Collins, C. G. (2014). Understanding heterogeneity in adaptation to retirement: A growth mixture modeling approach. International Journal of Aging and Human Development, 79(2), 131-156

Oishi, S., Diener, E., Suh, E., \& Lucas, R. E. (1999). Value as a moderator in subjective well-being. Journal of Personality, 67(1), 157-184

Pinquart, M., \& Schindler, I. (2007). Changes of life satisfaction in the transition to retirement: A latentclass approach. Psychology and Aging, 22(3), 442-455

Reitzes, D. C., \& Mutran, E. J. (2004). The transition to retirement: Stages and factors that influence retirement adjustments. International Journal of Aging and Human Development, 59(1), 63-84

Rokeach, M. (1973). The nature of human values. Free Press.

Sagiv, L., \& Schwartz, S. H. (2000). Value priorities and subjective well-being: Direct relations and congruity effects. European Journal of Social Psychology, 30(2), 177-198

Sagiv, L., Roccas, S., \& Hazan, O. (2004). Value pathways to well-being: Healthy values, valued goal attainment, and environmental congruence. In P. A. Linley \& S. Joseph (Eds.), Positive psychology in practice. (pp. 68-85). Wiley.

Schwartz, S. H. (1992). The universal content and structure of values: Theoretical advances and empirical tests in 20 countries. Advances in Experimental Social Psychology, 25(1), 1-65

Schwartz, S. H. (2012). An overview of the Schwartz theory of basic values. Online Readings in Psychology and Culture. https://doi.org/10.9707/2307-0919.1116

Schwartz S. H. (2020). Human values. Chapter 5 'Higher-order values'. Downloaded from http://essedunet. nsd.uib.no/cms/topics/1, May 2020.

Schwartz, S. H., Cieciuch, J., Vecchione, M., Davidov, E., Fischer, R., Beierlein, C., Ramos, A., Verkasalo, M., Lönnqvist, J.-E., Demirutku, K., Dirilen-Gumus, O., \& Konty, M. (2012). Refining the theory of basic individual values. Journal of Personality and Social Psychology, 103(4), 663-688 
Sedikides, C., \& Strube, M. J. (1995). The multiply motivated self. Personality and Social Psychology Bulletin, 21(12), 1330-1335

Slagsvold, B., Veenstra, M., Daatland, S., Hagestad, G., Hansen, T., Herlofson, K., Koløen, K., \& Solem, P. E. (2012). Life-course, ageing and generations in Norway: The NorLAG study. Norsk Epidemiologi, 22(2), 95-102

Szinovacz, M. E., \& Davey, A. (2006). Effects of retirement and grandchild care on depressive symptoms. International Journal of Aging and Human Development, 62(1), 1-20

van Solinge, H. (2013). Adjustment to retirement. In M. Wang (Ed.), The Oxford handbook of retirement. (pp. 311-324). Oxford University Press.

Wang, M. (2007). Profiling retirees in the retirement transition and adjustment process: Examining the longitudinal change patterns of retiree's psychological wellbeing. Journal of Applied Psychology, 92(2), 455-474

Wang, M., \& Shi, J. (2014). Psychological research on retirement. Annual Review of Psychology, 65, 209-233

Wang, M., Henkens, K., \& van Solinge, H. (2011). Retirement adjustment: A review of theoretical and empirical advancements. American Psychologist, 66(3), 204-213

Wanka, A. (2020). Continuity and change in the transition to retirement: How time allocation, leisure practices and lifestyles evolve when work vanishes in later life. European Journal of Ageing, 17(1), 81-93

Ware, J. E., Kosinski, M., \& Keller, S. D. (1996). A 12-Item short-form health survey: Construction of scales and preliminary tests of reliability and validity. Medical Care, 34(3), 220-233

Wetzel, M., Huxhold, O., \& Tesch-Römer, C. (2016). Transition into retirement affects life satisfaction: Short-and long-term development depends on last labor market status and education. Social Indicators Research, 125(3), 991-1009

World Economic Forum. (2020). Global gender gap report 2020. Switzerland.

Publisher's Note Springer Nature remains neutral with regard to jurisdictional claims in published maps and institutional affiliations. 